\title{
Effects of a 75-km mountain ultra-marathon on heart rate variability in amateur runners
}

\author{
Alberto CALLEJA-ROMERO ${ }^{1}$ *, Isaac LÓPEZ-LAVAL 1, Sebastian SITKO 1, David HERNANDO 2, 3 , \\ Germán VICENTE-RODRÍGUEZ 1, 4, 5, 6, Raquel BAILÓN 2, 3, Nuria GARATACHEA 1, 4, 5, 6, 7
}

${ }^{1}$ Department of Physiatry and Nursing, Faculty of Health and Sport Science (FCSD), University of Zaragoza, Huesca, Spain; ${ }^{2}$ BSICoS Group, Aragon Institute of Engineering Research (I3A), IIS Aragón, University of Zaragoza, Zaragoza, Spain; ${ }^{3} \mathrm{CIBER}$ - Bioengineering, Biomaterials and Nanomedicine (CIBER-BBN), Madrid, Spain; ${ }^{4}$ Growth, Exercise, Nutrition and Development Group, Faculty of Health and Sport Sciences, University of Zaragoza, Zaragoza, Spain; ${ }^{5}$ Centro de Investigación Biomédica en Red de Fisiopatología de la Obesidad y Nutrición (CIBER-Obn), Madrid, Spain; ${ }^{2}$ Instituto Agroalimentario de Aragón -IA2- (CITA-Universidad de Zaragoza), Zaragoza, Spain; ${ }^{7}$ National Sports Council, Madrid, Spain

*Corresponding author: Alberto Calleja-Romero, Department of Physiatry and Nursing, Faculty of Health and Sport Science (FCSD), University of Zaragoza, Pza. Universidad 3, 22002 Huesca, Spain. E-mail: calleja@unizar.es

\section{A B S T R A C T}

BACKGROUND: This study examined the effects of a mountain ultra-marathon (MUM) on the activity of the autonomous nervous system through heart rate variability (HRV) monitoring and determined whether this variable related to final performance.

METHODS: Heart rate and HRV were measured in eight male amateur runners (aged 37-60 years). Measurements were recorded before and after the event, in resting conditions, as well as continuously throughout the whole MUM. In addition, percentage (\%) of heart rate reserve (HR $\left.\mathrm{res}_{\text {res }}\right)$ and partial and total times during the race were analyzed.

RESULTS: Average heart rate (HR ${ }_{\text {avg }}$ ) measured at rest was increased after the event $(+37 \%)$. Standard deviation of successive differences (SDSD) and the square root of the mean squared differences of successive NN intervals (RMSSD) were reduced after the MUM (-56\% and $-59 \%$, respectively). There was a positive relationship between the frequency-domain index normalized low frequency power $\left(P_{L F n}\right)$ measured at rest before the event and race time (0.79) while there was a negative relationship between race time and the difference in $\mathrm{HR}_{\mathrm{avg}}$ before and after the event. In the last half of the event, there was a high correlation (Spearman coefficient of correlation $>0.9$ ) between race time and the standard deviation of the NN intervals (SDNN) registered during the race.

CONCLUSIONS: Autonomous cardiac regulation can be related to the performance in a mountain ultra-marathon. HRV monitoring could represent a practical tool for the evaluation of the relationship between the autonomous nervous system activity and performance in a mountain ultra-marathon.

(Cite this article as: Calleja-Romero A, López-Laval I, Sitko S, Hernando D, Vicente-Rodríguez G, Bailón R, et al. Effects of a 75-km mountain ultra-marathon on heart rate variability in amateur runners. J Sports Med Phys Fitness 2020;60:1401-7. DOI: 10.23736/S0022-4707.20.10860-0)

KEY wORDS: Autonomic nervous system; Cardiovascular physiological phenomena; Heart rate; Exercise; Running.

U ltra-endurance competitions have gained considerable popularity during the last years. Trail running events consist of running/walking on mountain trails with positive and negative slopes ${ }^{1}$ and may be performed across a great variety of distances. Mountain ultra-marathons (MUM), which are those that exceed marathon distance (>42,195 km), have become especially popular.1, 2 These competitions are characterized by their high intensity and large elevation gains, which are features that have attracted the attention of scientists. ${ }^{2}$ MUMs have been previously used for the study of adaptative responses to extreme competition load and stress in athletes. ${ }^{3}$

One of the preferred methods for measuring physiological adaptations in participants of ultra-endurance events (UEE) is heart rate variability (HRV).4-6 This variable provides information regarding the autonomous nervous sys- 


\section{COPYRIGHT $^{\odot} 2020$ EDIZIONI MINERVA MEDICA}

tem (ANS) function. ${ }^{7}$ Heart rate (HR) monitoring has been one of the most commonly used non-invasive methods in the last years due to its simplicity and convenience.4, 6, 8 Recent scientific literature has shown that HR monitoring is useful for evaluating physiological and psychological adaptations to different stressors in endurance sports ${ }^{9-11}$ and therefore can be used for assessing training, performance and well-being.

HRV as an indicator of ANS functioning has been previously studied during different stages of the competitive period: before/during breaks, ${ }^{12}$ during ${ }^{13}$ or after competition. ${ }^{14}$ ANS evaluation through monitoring of basal HR and HRV before a MUM has been previously used to predict performance. One study showed that lower HR in association with a higher vagal tone predicted a better performance in a $690 \mathrm{~km}$ MUM, revealed by the correlation between HR and the percentage of consecutive NN intervals larger than $50 \mathrm{~ms}$ with respect to the total number of NN intervals (pNN50+). ${ }^{9}$ Nevertheless, resting HRV showed inconsistent results when recreationally trained subjects were compared with those with an extensive training history. ${ }^{12}$ Furthermore, differences in athlete's resting HRV could theoretically be attributed to methodological factors such as the time of day at which measurements were taken or the assessment posture. Therefore, more research is required to fully deduce the impact of these methodological considerations. ${ }^{15}$ Changes in HRV during a MUM typically show an increase in sympathetic nervous system activation and a decrease in parasympathetic activity, as expected due to the stressful nature of the exercise. ${ }^{13}$ However, vagal tone recovery has been observed before the end of a very long MUM. ${ }^{9}$ After an UEE, HRV analysis showed parasympathetic predominance being gradually restored. This is due to vagal reactivation, which may be modulated by variables such as preceding exercise, training status and others. ${ }^{9}, 16-18$ For this reason, other studies are needed in order to achieve a more comprehensive knowledge about particular variables and their effect on HRV changes after UEE.

Despite scientific evidence regarding ANS modulation before and after an UEE,9, 12, 16-18 there are a lot of variables that could affect this process. HRV is associated with numerous external and internal factors, ${ }^{19}$ especially in stressful environments (e.g. mountain, substantial altitude variations, etc.) $)^{9}$ and, therefore, previous conclusions should be validated. ${ }^{9}$ Furthermore, the analysis and interpretation of HRV during UEE, still remains an important key point in the sports performance field as some studies conclude that breathing and HR are not constant during exercise and correction factors should therefore be applied before interpreting these results. ${ }^{20,}{ }^{21}$ The objective of the present study was to assess the activity of the ANS through HRV monitoring before, during and after a 75 km MUM event.

\section{Materials and methods}

\section{Participants}

Eight male amateur athletes who completed a $75 \mathrm{~km}$ MUM participated voluntarily in the present study. The event was the Canfranc-Canfranc (CC), which took place in the Spanish Pyrenees on September 8th, 2018. The study sample represented $11 \%$ of the finishing participants. All of them reside and train in their respective cities of residence (all below $1000 \mathrm{~m}$ altitude). None of them carried out altitude training camps before the competition.

The main characteristics of the study sample can be seen in Table I. One out of the 8 subjects that made up the study sample was 37 years old, 6 were in an age range between 40 and 48 and 1 subject was 60 years old.

All participants signed a written informed consent and provided data regarding their previous aerobic training experience. The study was designed according to the latest version of the Declaration of Helsinki22 and was previously approved by the Ethical Committee of the autonomous region of Aragon, Spain (ref. N04/2019).

\section{Inclusion and exclusion criteria}

The inclusion criteria were as follows: 1) male gender; 2) aged between 25 and 60 years; 3) participation in a marathon or ultra-marathon in the previous year; 4) nonsmoker; 5) familiar with HR monitor attached to the chest during training sessions.

Participants with diagnosed cardiovascular disease or those who presented one or several cardiovascular risk factors, history of surgery or trauma in the six months prior to the event were excluded from participating in the present study.

TABLE I.-Characteristics of the participants.

\begin{tabular}{lc}
\hline Variable & $\mathrm{N} .=8$ \\
\hline Age (years) & $47.8 \pm 7.4[37-60]$ \\
Body mass $(\mathrm{kg})$ & $73.6 \pm 4.7[62-79]$ \\
Height $(\mathrm{cm})$ & $178.4 \pm 5.5[170-185]$ \\
Body Mass Index $\left(\mathrm{kg} / \mathrm{m}^{2}\right)$ & $23.1 \pm 0.9[20.5-24.5]$ \\
Aerobic Training Experience (years) & $8.6 \pm 6.0[4-19]$ \\
Mean week running kilometers (km/week) & $55.2 \pm 8.7[50-70]$ \\
\hline
\end{tabular}

Data are expressed as mean and standard deviation \pm SD and range (extremes of data set [min-max]). 


\section{COPYRIGHT $^{\odot} 2020$ EDIZIONI MINERVA MEDICA}

\section{Procedures}

The running distance was $75 \mathrm{~km}$, with a positive elevation gain of $6500 \mathrm{~m}$ and a maximal altitude of $2645 \mathrm{~m}$. Figure 1 graphically shows the number of kilometers covered by altitude sections and their corresponding total distance percentage.

The race had 5 feeding points in which solid and liquid meals were provided. The CC Organization tracked and provided the split times of all participants in 8 intermediate points, in addition to the official final time. Profile of the CC, as well as intermediate points where time was registered can be seen in Figure 2.

\section{Evaluation}

First, participants completed a questionnaire about their aerobic training history.

Each participant wore a Polar Team Pro Sensor ${ }^{\circledR}$ (Polar Electro, Kempele, Finland) HR chest belt. This system detects heartbeat time occurrences from an ECG recorded at a sampling rate of $1000 \mathrm{~Hz} .{ }^{23} \mathrm{HR}$ chest belts were placed following the recommendations of the manufacturer, below the pectoralis muscles. HR was monitored continuously starting two hours before the MUM and up to thirty minutes after the end. All data were recorded in the memory of the HR chest belt and were downloaded using the software provided by the manufacturer (Polar ${ }^{\circledR}$ Team Manager). RR interval series were obtained and recorded for statistical analysis.

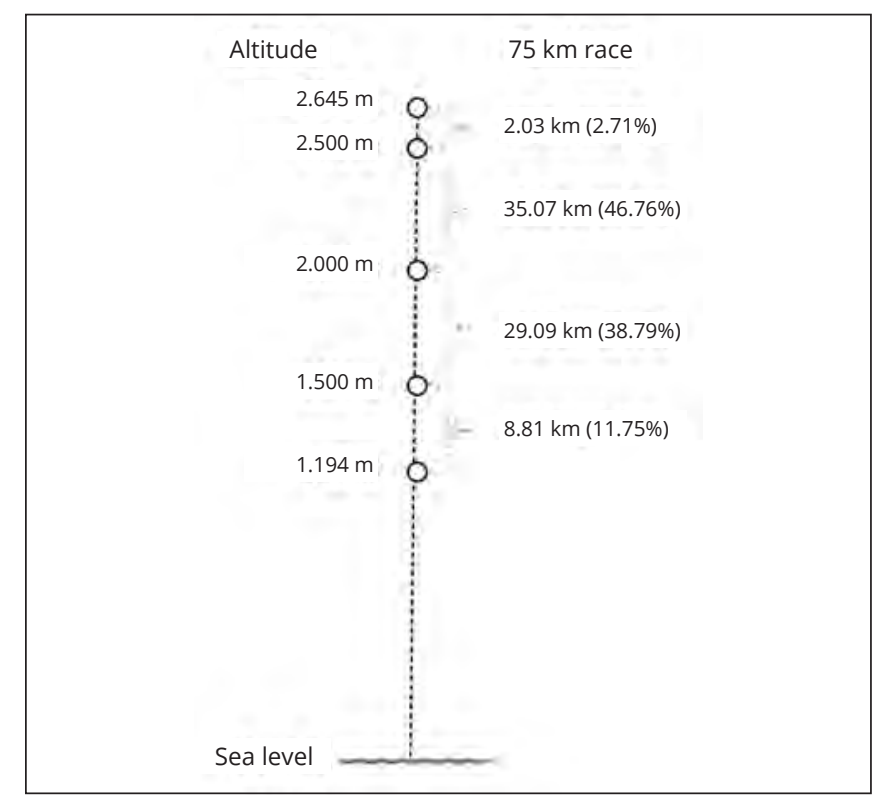

Figure 1.- Race altitude.

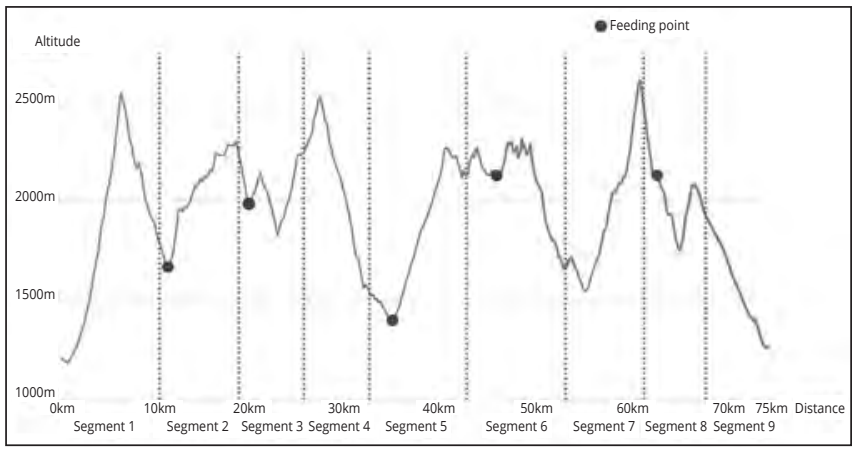

Figure 2.--Race profile.

Ten min HR baseline recording was performed by HR chest belt $2 \mathrm{~h}$ prior (PRE) and 20min after (POST) the race in a climate-controlled room (temperature of $23{ }^{\circ} \mathrm{C}$ and humidity of 52\%) with a calm environment. Participants were in supine position and were instructed to not speak nor move and breathe normally during the recording, following the protocol used in previous studies. ${ }^{11,12}$ Special emphasis was placed to accurately follow the protocol for PRE and POST recordings. HR was also recorded during the entire race (DURING).

HR data collected from the HR chest belt was completed with information regarding split times during the event (8 points), and the official finishing time. Race times also included provisioning times (Figure 3).

\section{HR and HRV analysis}

Maximal HR was estimated using the formula: $\mathrm{HR}_{\max }=$ age (208-0.7*age). ${ }^{24}$ The exercise intensity was calculated from the exercise $\mathrm{HR}\left(\mathrm{HR}_{\text {exe }}\right)$ as a percentage of the reserve $\mathrm{HR}$ $\left(\mathrm{HR}_{\mathrm{res}}\right)$ of each athlete, following the Karvonen formula: \% $\mathrm{HR}_{\text {res }}=100 *\left(\mathrm{HR}_{\text {exe }}-\mathrm{HR}_{\text {rest }}\right) /\left(\mathrm{HR}_{\text {max }}-\mathrm{HR}_{\text {rest }}\right){ }^{25}$

Outlier RR intervals were identified based on a timevarying threshold using instantaneous $\mathrm{HR}$ variation, ${ }^{26}$ from which normal-to-normal (NN) interval series were obtained. Time-domain indices were derived from the NN interval series according to the Task Force guideline.27, 28

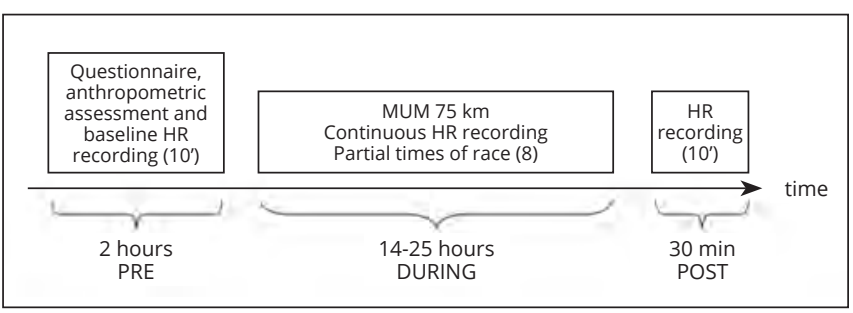

Figure 3.-Schematic representation of the experimental protocol. 


\section{COPYRIGHT $^{(} 2020$ EDIZIONI MINERVA MEDICA}

The following indices were computed in each segment (PRE, POST and the 9 segments in which the race was divided): the average $\mathrm{HR}\left(\mathrm{HR}_{\mathrm{avg}}\right)$, the standard deviation of the NN intervals (SDNN), the standard deviation of successive differences (SDSD), and the square root of the mean squared differences of successive NN intervals (RMSSD). Frequency-domain indices were obtained from the modulating signal (sampled at $4 \mathrm{~Hz}$ ) derived from the RR interval series. The methodology used was based on the time-varying integral pulse frequency modulation model, which considers the presence of outlier RR intervals and accounts for the influence of mean heart rate. ${ }^{29}$ Power in the low and high frequency bands $\left(P_{L F}\right.$ and $P_{H F}$, respectively) was established as follows: Low frequency band ranged from 0.04 to $0.15 \mathrm{~Hz}$; high frequency band ranged from 0.15 to 0.5 of the mean HR, with the purpose to capture the spectral components synchronous with respiration, expected to be above the classic limit of $0.4 \mathrm{~Hz}$ during exercise. Additionally, the normalized low frequency power $\left(P_{L F n}=P_{L F} /\left(P_{L F}+P_{H F}\right)\right)$ was estimated. ${ }^{27}$

The former HRV indices were computed on the 5 central minutes of the PRE and POST recordings, where stationarity of HRV is assumed. During the race, HRV indices were computed with the following considerations: 1) time-domain indices were computed on each segment of the race; 2) frequency-domain indices were computed on non-overlapping 5-minute windows; 30 then, each segment was characterized by the mean and standard deviation of the 5-minute window value indices.

\section{Statistical analysis}

Normality was checked with the Kolmogorov-Smirnov Test. Differences between HRV values in the POST and PRE recordings were assessed by Wilcoxon paired ranked test. Spearman correlation was computed between the total race time and HRV indices estimated from the PRE recordings, as well as their variations at the end of the race (POST-PRE). Then, the correlation between estimated HRV indices and times for each segment of the race was analyzed. For the statistically significant cases a post-hoc analysis was performed with the Student's $t$-test for paired samples. In all the analysis a $\mathrm{P}$ value $(\mathrm{P}<0.05)$ was considered for statistical significance.

\section{Results}

The mean race time was $19.01 \pm 3.35 \mathrm{~h}$ [14.91 to 24.52] (Table II). Basal HRV values are presented in Table III. PRE and POST measurements showed that after the race
TABLE II.-Description of the race segments.

\begin{tabular}{lccc}
\hline Segment & Distance $(\mathrm{km})$ & $\begin{array}{c}\text { Positive } \\
\text { elevation }(\mathrm{m})\end{array}$ & $\begin{array}{c}\text { Negative } \\
\text { elevation }(\mathrm{m})\end{array}$ \\
\hline 1 & 10.6 & 1423 & 953 \\
2 & 8.5 & 754 & 457 \\
3 & 7.1 & 896 & 316 \\
4 & 7.2 & 40 & 1210 \\
5 & 10.3 & 1133 & 394 \\
6 & 10.5 & 523 & 1064 \\
7 & 7.9 & 940 & 590 \\
8 & 6.6 & 533 & 556 \\
9 & 6.3 & 36 & 760 \\
\hline
\end{tabular}

there was a significant increase in the mean HR $(+37 \%$, $\mathrm{P}<0.05)$, and a significant drop in SDSD $(-56 \% \mathrm{P}<0.05)$ and RMSSD $(-59 \%, \mathrm{P}<0.05)$.

The relationship between race time and HRV indices calculated from both PRE and the difference between POST and PRE (POST-PRE) is presented in Table IV. Basal HRV correlated positively to $P_{L F n}$ and total race time $(0.79, \mathrm{P}<0.05)$. Regarding the difference between POSTPRE HRV, a negative relationship was observed between $\mathrm{HR}_{\mathrm{avg}}$ and race time $(-0.79, \mathrm{P}<0.05)$.

As for the predefined segments, a positive relationship was found between time employed in segments 4, 5, 6, 7 and 8 and the SDNN index of the HRV (Table V). There was also a negative relationship between SDNN and \% $\mathrm{HR}_{\text {res }}$ on the segments $7(-0.93, \mathrm{P}<0.05)$ and $8(-0.86$, $\mathrm{P}<0.05$ ).

\section{Discussion}

The present study evaluated the effects of a $75 \mathrm{~km}$ MUM on HRV of amateur endurance runners. The main results of the study were that: 1 ) sympathetic activity was increased after the race, shown by increased $\mathrm{HR}_{\mathrm{avg}}$ and decreased SDSD and RMSSD; 2) the analysis of $P_{L F n}$ before the race, as an indicator of sympathetic modulation, correlated positively with race time. This means that the higher the sympathetic activity before the race, the more time was needed to complete it; 3) race time correlated negatively with the difference between before and after race resting $\mathrm{HR}_{\mathrm{avg}}$. In other words, slower participants showed less increase in $\mathrm{HR}_{\mathrm{avg}}$ at the end of the race in comparison to their $\mathrm{HR}_{\mathrm{avg}}$ before the race; 4) lastly, another interesting finding was detected as a result of the continuous recording throughout the whole race: there was a high correlation (Spearman coefficient of correlation $>0.9$ ) between race time during the second half of the event (segments 4 to 8 out of 9) and the SDNN registered during these segments, meaning that 


\section{COPYRIGHT $^{\odot} 2020$ EDIZIONI MINERVA MEDICA}

MOUNTAIN ULTRA-MARATHON AND HR VARIAVILITY

CALLEJA-ROMERO

TABLE III.-HRV variables during the PRE and POST recordings.

\begin{tabular}{lcccccc}
\hline & $\mathrm{HR}_{\text {avg }}(\mathrm{bpm})$ & SDNN $(\mathrm{ms})$ & SDSD $(\mathrm{ms})$ & RMSSD (ms) & PLFn (n.u) & PHF (ad) x e ${ }^{-4}$ \\
\hline PRE & $51 \pm 2$ & $43 \pm 25$ & $32 \pm 25$ & $32 \pm 25$ & $0.50 \pm 0.25$ & $3.4 \pm 4.0$ \\
POST & $70 \pm 13$ & $25 \pm 21$ & $14 \pm 12$ & $13 \pm 12$ & $0.65 \pm 0.25$ & $0.5 \pm 1.4$ \\
P value & $0.0156^{*}$ & 0.0781 & $0.0156^{*}$ & $0.0156^{*}$ & 0.4688 & 0.4688 \\
\hline
\end{tabular}

Data are expressed as mean and standard deviation $( \pm \mathrm{SD})$.

Heart rate variability (HRV) variables during the baseline recording (PRE) and after race recording (POST), and P value obtained by Wilcoxon paired ranked test are displayed with *, P values $<0.05$.

HRavg: average heart rate; SDNN: standard deviation of the NN intervals; SDSD: standard deviation of successive differences; RMSSD: square root of the mean squared differences of successive NN intervals; PLFn: normalized power in the low frequency bands in normalized units; PHF: power in the high frequency bands.

TABLE IV.-Spearman correlation coefficient between the total time of the race and each HRV index during the PRE recording and difference between the POST and PRE recordings.

\begin{tabular}{lcccccc}
\hline & $\mathrm{HR}_{\text {avg }}(\mathrm{bpm})$ & SDNN $(\mathrm{ms})$ & SDSD $(\mathrm{ms})$ & RMSSD $(\mathrm{ms})$ & PLFn $(\mathrm{n} . \mathrm{u})$ & PHF $(\mathrm{ad}) \mathrm{x} \mathrm{e}^{-4}$ \\
\hline PRE & -0.21 & -0.14 & -0.46 & -0.46 & $0.79^{*}$ & -0.64 \\
POST-PRE & $-0.79 *$ & -0.03 & 0.18 & 0.18 & -0.54 & 0 \\
\hline
\end{tabular}

HRavg: average heart rate; SDNN: standard deviation of the NN intervals; SDSD: standard deviation of successive differences; RMSSD: square root of the mean squared differences of successive NN intervals; PLFn: normalized power in the low frequency bands in normalized units; PHF: power in the high frequency bands.

*Statistically significant correlations.

TABLE V.-Spearman correlation coefficient between SDNN and the time of each segment and running intensity calculated from the running heart rate $\left(H R_{\text {exe }}\right)$ as a percentage of the reserve heart rate $\left(H R_{\text {res }}\right.$.

\begin{tabular}{lccccccccc}
\hline & Segment 1 & Segment 2 & Segment 3 & Segment 4 & Segment 5 & Segment 6 & Segment 7 & Segment 8 & Segment 9 \\
\hline Time & -0.21 & 0.61 & 0.68 & $0.79 *$ & $0.93^{*}$ & $0.93 *$ & $0.93 *$ & $0.89 *$ & 0.32 \\
Intensity & -0.07 & -0.36 & -0.61 & 0.07 & -0.75 & -0.46 & $-0.93^{*}$ & $-0.86^{*}$ & -0.25 \\
\hline
\end{tabular}

*Statistically significant correlations.

less sympathetic activation resulted in a slower pace in the second half of the event, or vice versa.

The increase of $\mathrm{HR}_{\mathrm{avg}}(+37 \%)$ and also the reduction in time-domain variables of the HRV such as SDSD (-56\%) and RMSSD (-59\%) observed after the end of the race are in line with current scientific evidence regarding cardiovascular control after exercise. In previous studies, such as Gratze et al.,16 a $27 \%$ increase in the $\mathrm{HR}_{\mathrm{avg}}$ was observed one hour after the end of an Ironman (10.98 hours of racing). Similarly, Murrell et al. ${ }^{31}$ reported a $35 \% \mathrm{HR}_{\mathrm{avg}}$ increase 3 to 5 hours after the end of a mountain marathon (4.35 hours of racing). Considering this, the $37 \% \mathrm{HR}_{\mathrm{avg}}$ increase after MUM observed in the current study is consistent with previous findings that suggest that sympathetic activation due to high intensity endurance exercise can be observed after the end of the activity (30 minutes in this case). Likewise, the decrease in SDSD, which represents short-term variability (SDNN), 32 and the decrease in RMSSD after endurance events have been reported previously such as in the study performed by Foulds et al., ${ }^{18}$ with observed decreases of 52\% in SDNN and $42 \%$ in RMSSD after ultra-marathons. This evidence suggests that the homeostasis disruption produced by high intensity endurance events induces changes in the ANS, a finding that reflects the increased sympathetic modulation during this type of exercise. ${ }^{18}$ This can be observed even after the exercise period has finished. These changes, as an acute effect of ultra-endurance efforts, may play a role in cardiac adaptations in this type of exercise. ${ }^{13,33}$

Regarding the basal values studied before the event, the HRV analysis through frequency-domain methods established a positive correlation between race time and $P_{L F n}$. On a more practical level, this meant that the participants with higher $P_{L F n}$ values before the event performed worse (0.79, $\mathrm{P}<0.05)$. One possible cause of this relationship could be the precompetitive anxiety, which has been previously linked to changes in HRV towards sympathetic activation in athletes. Cervantes et al. ${ }^{34}$ reported that the low frequency (LF) components were higher in swimmers during competitive periods than during training periods. One possible cause of this could be that stress management before the event may have influenced performance. These results are in line with previous evidence that suggests a moderate relationship ( $r=0.10)$ between cognitive anxiety and sports performance, as described by Woodmand and Hardy 35 in their meta-analysis of 48 studies. Although other more re- 


\section{COPYRIGHT $^{\circledR} 2020$ EDIZIONI MINERVA MEDICA}

cent studies have not established a statistically significant relationship between performance and cognitive anxiety, ${ }^{36}$ the results of the present study could be explained by the hypothesis proposed by Raglin JS, ${ }^{37}$ who suggested that the relationship between precompetitive anxiety and performance could be influenced by several different factors such as the sports modality, self-confidence and even the negative or positive perception of anxiety. ${ }^{35}$ Considering all of this, the results of our study suggest that the participants with the lowest LF power before the event (which has been linked to optimal stress management before competitions) performed better during a $75 \mathrm{~km}$ MUM.

The correlation obtained between the difference in POST-PRE $H_{\mathrm{avg}}$ and race time could be contextualized by considering that a significant relationship between the SDNN during the second part of the event (segments 4 to 8) and race time was also found. Assuming SDNN as an indicator of HRV,38 this result shows that the slowest participants during the last part of the event (when compared to total race time), also showed lower sympathetic activation during the second half and reported lower POST $\mathrm{HR}_{\mathrm{avg}}$ when compared to PRE HR $\mathrm{Hvg}_{\mathrm{avg}}$. Regarding these results, Franco et al. 39 observed a negative correlation between the HR increase during a marathon and race time $(r=-0.5 ; \mathrm{P}=0.05)$, with slower athletes showing lower sympathetic activation during the race as evidenced by a lower increase in HR. Taking into account the duration of the race analyzed in the current study (average of $19.01 \mathrm{~h}$ ), self-pacing could produce a variation in the physiological responses of the athlete. Therefore, a possible explanation for this correlation is the fact that the participants with worse performance in the second half of the event were also characterized by lower relative intensities during this part. A significantly higher SDNN in segments 5 to 8 and lower $\mathrm{HR}_{\text {res }}$ in the final part of race supports this explanation. Rudfeldt et al. ${ }^{9}$ observed a recovery in vagal tone after a 690k ultra-marathon, hypothesizing that this phenomenon could be explained by the length of the race. The positive correlation between SDNN and race time found in the present study could add a new factor to this hypothesis: pace reduction during the event could influence vagal tone recovery before the end of the race. The increasingly lower intensities seen in the second half of the race could explain the reduced vagal tone recovery that was observed.

\section{Limitations of the study}

This study was conducted with a small sample size. Despite this, we consider that a study sample that represented $11 \%$ of the total race finishers reports meaningful informa- tion on this type of extreme conditions. Regarding HRV analysis in long distance athletes, there is enough scientific evidence to rely on for its interpretation during resting, however there is a lot of controversy around its interpretation during an effort. Future studies should emphasize on the interpretation of ANS through HRV analysis during exercise to confirm or clarify the conclusions of this study.

\section{Conclusions}

HRV analysis provides valuable information concerning the activity of the ANS in amateur runners before, during and after a $75 \mathrm{~km}$ MUM.

According to the results of this study, increased sympathetic modulation before the race, denoted by $P_{L F n}$ analysis, predicts subsequent worse performance. Sympathetic activity is increased during a MUM and this can be observed even at the end of the race by an increased $\mathrm{HR}_{\mathrm{avg}}$ and decreased SDSD and RMSSD. Despite this, lower sympathetic activation resulted in a slower pace during the second half of the race, indicated by a high correlation between SDNN and race time during this segment.

Monitoring HRV in endurance athletes is, therefore, a useful and affordable tool for the assessment of cardiac autonomic regulation linked to race performance.

\section{References}

1. Saugy J, Place N, Millet GY, Degache F, Schena F, Millet GP. Alterations of Neuromuscular Function after the World's Most Challenging Mountain Ultra-Marathon. PLoS One 2013;8:e65596.

2. Millet GY, Martin V, Temesi J. The role of the nervous system in neuromuscular fatigue induced by ultra-endurance exercise. Appl Physiol Nutr Metab 2018;43:1151-7.

3. Millet GP, Millet GY. Ultramarathon is an outstanding model for the study of adaptive responses to extreme load and stress. BMC Med 2012;10:77.

4. Sztajzel J, Jung M, Sievert K, Bayes De Luna A. Cardiac autonomic profile in different sports disciplines during all-day activity. J Sports Med Phys Fitness 2008;48:495-501.

5. Bosquet L, Papelier Y, Léger L, Legros P. Night heart rate variability during overtraining in male endurance athletes. J Sports Med Phys Fitness 2003;43:506-12.

6. Sala R, Malacarne M, Tosi F, Benzi M, Solaro N, Tamorri S, et al. May a unitary autonomic index help assess autonomic cardiac regulation in elite athletes? Preliminary observations on the national Italian Olympic committee team. J Sports Med Phys Fitness 2017;57:1702-10.

7. Plews DJ, Laursen PB, Stanley J, Kilding AE, Buchheit M. Training adaptation and heart rate variability in elite endurance athletes: opening the door to effective monitoring. Sports Med 2013;43:773-81.

8. Cipryan L, Vala R. Cardiac autonomic regulation after continuous and intermittent maximal exercise interventions. J Sports Med Phys Fitness 2015;55:495-505.

9. Rundfeldt LC, Maggioni MA, Coker RH, Gunga HC, Riveros-Rivera A, Schalt A, et al. Cardiac Autonomic Modulations and Psychological 


\section{COPYRIGHT $^{(\odot)} 2020$ EDIZIONI MINERVA MEDICA}

Correlates in the Yukon Arctic Ultra: The Longest and the Coldest Ultramarathon. Front Physiol 2018;9:35.

10. Bellenger CR, Karavirta L, Thomson RL, Robertson EY, Davison K, Buckley JD. Contextualizing Parasympathetic Hyperactivity in Functionally Overreached Athletes With Perceptions of Training Tolerance. Int J Sports Physiol Perform 2016;11:685-92.

11. Buchheit M. Monitoring training status with HR measures: do all roads lead to Rome? Front Physiol 2014;5:73.

12. Singh N, Moneghetti KJ, Christle JW, Hadley D, Froelicher V, Plews D. Heart Rate Variability: An Old Metric with New Meaning in the Era of Using mHealth technologies for Health and Exercise Training Guidance. Part Two: Prognosis and Training. Arrhythm Electrophysiol Rev 2018;7:247-55.

13. Ramos-Campo DJ, Ávila-Gandía V, Alacid F, Soto-Méndez F, Alcaraz PE, López-Román FJ, et al. Muscle damage, physiological changes, and energy balance in ultra-endurance mountain-event athletes. Appl Physiol Nutr Metab 2016;41:872-8.

14. Kaikkonen P, Rusko H, Martinmäki K. Post-exercise heart rate variability of endurance athletes after different high-intensity exercise interventions. Scand J Med Sci Sports 2008;18:511-9.

15. Bellenger CR, Fuller JT, Thomson RL, Davison K, Robertson EY, Buckley JD. Monitoring Athletic Training Status Through Autonomic Heart Rate Regulation: A Systematic Review and Meta-Analysis. Sports Med 2016;46:1461-86.

16. Gratze G, Rudnicki R, Urban W, Mayer H, Schlögl A, Skrabal F Hemodynamic and autonomic changes induced by Ironman: prediction of competition time by blood pressure variability. J Appl Physiol (1985) 2005;99:1728-35.

17. Scott JM, Esch BT, Shave R, Warburton DE, Gaze D, George K. Cardiovascular consequences of completing a $160-\mathrm{km}$ ultramarathon. Med Sci Sports Exerc 2009;41:26-34.

18. Foulds HJ, Cote AT, Phillips AA, Charlesworth SA, Bredin SS, Burr $\mathrm{JF}$, et al. Characterisation of baroreflex sensitivity of recreational ultraendurance athletes. Eur J Sport Sci 2014;14:686-94.

19. Shaffer F, McCraty R, Zerr CL. A healthy heart is not a metronome: an integrative review of the heart's anatomy and heart rate variability. Front Psychol 2014;5:1040.

20. Bailón R, Garatachea N, de la Iglesia I, Casajús JA, Laguna P. Influence of running stride frequency in heart rate variability analysis during treadmill exercise testing. IEEE Trans Biomed Eng 2013;60:1796-805.

21. Hernando D, Hernando A, Casajús JA, Laguna P, Garatachea N, Bailón R. Methodological framework for heart rate variability analysis during exercise: application to running and cycling stress testing. Med Biol Eng Comput 2018;56:781-94.

22. General Assembly of the World Medical Association. World Medical Association Declaration of Helsinki: ethical principles for medical research involving human subjects. J Am Coll Dent 2014;81:14-8.

23. Barbosa MP, da Silva NT, de Azevedo FM, Pastre CM, Vanderlei LC. Comparison of Polar ${ }^{\circledR}$ RS800G3 ${ }^{\mathrm{TM}}$ heart rate monitor with Polar ${ }^{\circledR}$ S810i $\mathrm{i}^{\mathrm{TM}}$ and electrocardiogram to obtain the series of RR intervals and analysis of heart rate variability at rest. Clin Physiol Funct Imaging 2016;36:112-7.
24. Tanaka H, Monahan KD, Seals DR. Age-predicted maximal heart rate revisited. J Am Coll Cardiol 2001;37:153-6.

25. Karvonen MJ, Kentala E, Mustala O. The effects of training on heart rate; a longitudinal study. Ann Med Exp Biol Fenn 1957;35:307-15.

26. Mateo J, Laguna P. Analysis of heart rate variability in the presence of ectopic beats using the heart timing signal. IEEE Trans Biomed Eng 2003;50:334-43.

27. Task Force of the European Society of Cardiology and the North American Society of Pacing and Electrophysiology. Heart rate variability: standards of measurement, physiological interpretation and clinical use. Circulation 1996;93:1043-65.

28. Sassi R, Cerutti S, Lombardi F, Malik M, Huikuri HV, Peng CK, et al. Advances in heart rate variability signal analysis: joint position statement by the e-Cardiology ESC Working Group and the European Heart Rhythm Association co-endorsed by the Asia Pacific Heart Rhythm Society. Europace 2015;17:1341-53.

29. Bailón R, Laouini G, Grao C, Orini M, Laguna P, Meste O. The integral pulse frequency modulation model with time-varying threshold: application to heart rate variability analysis during exercise stress testing. IEEE Trans Biomed Eng 2011;58:642-52.

30. Bailón R, Serrano P, Laguna P. Influence of time-varying mean heart rate in coronary artery disease diagnostic performance of heart rate variability indices from exercise stress testing. J Electrocardiol 2011;44:445-52.

31. Murrell C, Wilson L, Cotter JD, Lucas S, Ogoh S, George K, et al. Alterations in autonomic function and cerebral hemodynamics to orthostatic challenge following a mountain marathon. J Appl Physiol (1985) 2007;103:88-96.

32. Shaffer F, Ginsberg JP. An Overview of Heart Rate Variability Metrics and Norms. Front Public Health 2017;5:258.

33. Clemente-Suárez VJ. Psychophysiological response and energy balance during a 14-h ultraendurance mountain running event. Appl Physiol Nutr Metab 2015;40:269-73.

34. Cervantes Blásquez JC, Rodas Font G, Capdevila Ortís L. Heartrate variability and precompetitive anxiety in swimmers. Psicothema 2009;21:531-6.

35. Woodman T, Hardy L. The relative impact of cognitive anxiety and self-confidence upon sport performance: a meta-analysis. J Sports Sci 2003;21:443-57.

36. Fortes LS, da Costa BD, Paes PP, do Nascimento Júnior JR, Fiorese L, Ferreira ME. Influence of Competitive-Anxiety on Heart Rate Variability in Swimmers. J Sports Sci Med 2017;16:498-504.

37. Raglin JS. Anxiety and sport performance. Exerc Sport Sci Rev 1992;20:243-74.

38. Task Force of the European Society of Cardiology and the North American Society of Pacing and Electrophysiology. Heart rate variability: standards of measurement, physiological interpretation and clinical use. Circulation 1996;93:1043-65.

39. Franco V, Callaway C, Salcido D, McEntire S, Roth R, Hostler D. Characterization of electrocardiogram changes throughout a marathon. Eur J Appl Physiol 2014;114:1725-35.

Conflicts of interest.-The authors certify that there is no conflict of interest with any financial organization regarding the material discussed in the manuscript. Authors'contributions.-All authors read and approved the final version of the manuscript. Alberto Calleja-Romero and Isaac López-Laval contributed to the study by planning, performing measurements and data collection, analyzing the data and writing the manuscript; Sebastian Sitko assisted with the measurements and data collection and revised the manuscript; David Hernando and Raquel Bailón performed statistical analysis, analyzed the data, assisted with the interpretation of results and revised the manuscript; Germán Vicente-Rodríguez and Nuria Garatachea contributed to the study design, provided expertise and feedback and revised the manuscript.

History.-Article first published online: June 18, 2020. - Manuscript accepted: June 8, 2020. - Manuscript revised: June 3, 2020. - Manuscript received: February 21, 2020. 